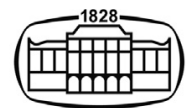

AKADÉMIAI KIADÓ

Developments in Health Sciences

$3(2020) 3,58-64$

DOI:

$10.1556 / 2066.2020 .00011$

(c) 2020 The Author(s)

ORIGINAL RESEARCH PAPER

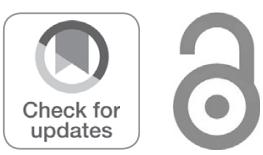

\title{
Effectiveness of a Hungarian peer education handwashing programme in primary and secondary schools
}

\author{
ZS. MOLNÁR ${ }^{1}$, L. VARGA ${ }^{1}$, G. GYENES ${ }^{1}$, Á. LEHOTSKY ${ }^{2}$, \\ E. GRADVOHL ${ }^{1}$, Á.J. LUKÁCS ${ }^{1}$, R.A. FÜZI ${ }^{3}$, A. GÉZSI ${ }^{4,5}$, \\ A. FALUS ${ }^{6}$ and H.J. FEITH ${ }^{1^{*}}$ \\ ${ }^{1}$ Department of Social Sciences, Faculty of Health Sciences, Semmelweis University, Budapest, \\ Hungary \\ ${ }^{2}$ National Institute of Oncology, Budapest, Hungary \\ ${ }^{3}$ Department of Public Health, Government Office of the Capital City Budapest, Budapest, Hungary \\ ${ }^{4}$ MTA-SE Immune-Proteogenomic Extracellular Vesicle Research Group, Budapest, Hungary \\ ${ }^{5}$ Department of Measurement and Information Systems, Budapest University of Technology and \\ Economics, Budapest, Hungary \\ ${ }^{6}$ Department of Genetics, Cell- and Immunobiology, Faculty of Medicine, Semmelweis University, \\ EDUVITAL Foundation, Budapest, Hungary
}

Received: March 29, 2020 • Revised manuscript received: July 13, 2020 • Accepted: September 29, 2020

Published online: November 19, 2020

\begin{abstract}
Purpose: Proper handwashing helps prevent the spread of communicable diseases. The aim of our study was to analyse and compare children's knowledge and skills in hand hygiene before and after school interventions in order to evaluate the effectiveness of our peer education programme. Materials/ methods: In our longitudinal study, short- and long-term changes in the knowledge, hand-washing skills and health behaviour of 224 lower, upper and secondary school students were assessed. Our measurements were performed with a self-administered, anonymous questionnaire and the Semmelweis Scanner. Results: As a result of the intervention, the proportion of correct answers increased significantly both in the short term and in the long run compared to the input measurements, but age differences did not disappear for most variables. There is a difference in the process of learning theoretical knowledge and practical skills. Areas not used for handwashing in the paediatric population are different from those described for adults in the literature. There was no significant difference between the mean scores of the right and left hands. Conclusions: There was a significant positive change in both theory and practice of handwashing. In education, emphasis should also be put on long-term retention of theoretical knowledge in age-specific health promotion programmes within the paediatric population.
\end{abstract}

\section{KEYWORDS}

hand-hygiene, handwashing skills, handwashing knowledge, peer education, school intervention

*Corresponding author. Department of Social Sciences, Faculty of Health Sciences, Semmelweis University Vas utca 17, Budapest, $\mathrm{H}-1088$, Hungary. E-mail: feith@se-etk.hu

\section{INTRODUCTION}

Numerous studies established earlier the associations between handwashing and the prevalence of distinct infections $[1,2]$. Person-to-person transmission via hands and contaminated objects plays a key role in the spread of infections [3]. Previous studies investigating the most frequently missed areas in adult population found that right-handed people have more leftsided areas on the dorsal area of the right hand [4-7]. Although handwashing is a simple and efficient method for reducing the risk of communicable diseases, certain viruses and other 
infectious agents, studies have shown the relatively low adherence to the recommended handwashing protocols [8$10]$.

Several studies conducted worldwide have discussed the problem of general hygiene and handwashing among students [11-13]. In line with this, the important role of handwashing and health education has been highlighted in promoting adequate handwashing, as a relevant contribution to breaking the transmission cycle of distinct infections [14].

Research studies among children showed that students, who followed the appropriate hand-hygiene rules, missed less school hours because of any illness, although many research studies were not well executed or reported [15-18]. Prevention is an effective, simple and cheap method of reducing the prevalence of infections, in which proper handwashing plays a vital role. This conclusion is the most important intellectual heritage of Ignaz Semmelweis (18181865) [19]. The earlier education starts in childhood, the more efficient it becomes, so it is recommended to develop children's hygienic behaviour from the first school years on. It is important to note that adoption of a health behaviour and turning it into a habit are predicted by social-cognitive factors, such as attitude, subjective norms and self-efficacy beliefs [20-23].

Because the young, developing children are more likely to get any communicable disease due to their lifestyle and not fully developed immune system, we aimed to develop and test an effective peer-education programme in the field of handwashing $[24,25]$.

During properly supervised and executed peer education students open up and talk freely and positive behavioural changes can be detected among them [23, 26]. Young generations have "good" opinions about peer education-based health promotion programmes; therefore, these programmes are recommended in these age groups [24, 27]. Through peer education, "lecturers" focus on developing practical skills using interactive tasks considering the receptiveness and learning strategies of the age groups.

The purpose of this study is to analyse and compare children's knowledge and skills in hand hygiene before and after four-lesson peer education programmes in school environment.

\section{MATERIALS AND METHODS}

The STAnD (which is an acronym of the following words: Study, Teach, Understand) peer educational programme is a programme of the Hungarian Academy of Sciences with different target issues in health promotion (e.g. fluid consumption, internet addiction, basic life support) [22]. One of the STAnD Programmes is the Hand Washing Programme (SHWP). The aim of the SHWP was (1) to teach 6-18-yearold children in a four-hour-long school health day programme the six-step WHO handwashing technique, which has been proven effective $[25,28]$ and $(2)$ to develop their health-conscious behaviour relating to hand hygiene.
In the first part of SHWP there was an elective preliminary training course for future peer educator students. In the 24-lesson preparatory courses, which were elective trainings in healthcare and teacher training higher education institutions, the students (1) were able to acquire essential knowledge, innovative, cooperative learning and teaching methods and (2) developed their own active, creative and playful prevention programme plans under tutor control. In the second part of our programme handwashing programmes were delivered to the target population on school health days by teams of four peer educators. We used questionnaire-based and physical measurement-based research methods in the second part of SHWP to measure the effectiveness of the hand hygiene training programmes and the impact of these health promotion interventions [25]. The anonymous, self-administered and - structured questionnaire focused on basic socio-demographic data, selfperceived health status, knowledge and health behaviour in terms of handwashing habits [25]. The physical measurement-based research instrument, the Semmelweis Scanner (by HandinScan Ltd. 2018, Budapest) - a mobile digital and control device was used in our programmes to objectively evaluate the effectiveness of children's handwashing techniques $[6,28,29]$. In the physical measurement-based research 20-20 parts of left and rights hands were examined in every child. The short- and long-term effects of the handwashing techniques were measured by the Semmelweis Scanner and analysed by an expert of our research group at three times: before the intervention (Input) and right after the intervention (Output 1), as well as four months after the intervention (Output 2) [25].

The target population of the SHWP was formed from two primary and two secondary schools. In Hungary, the primary schools are divided in two sections: lower primary school (approx. 6-10-year-old children) and upper primary school (approx.10-14-year-old children). 464 children took part in our four-lesson school prevention programmes and filled out our questionnaires before the intervention (Input) and right after the intervention (Output 1), as well as four months after the intervention (Output 2), but only 224 children's handwashing techniques were measured by the Semmelweis Scanner. In our present sample 42.9\% $(n=$ $199)$ of the participants were boys and $56.9 \%$ girls $(n=264)$. Half of the students were from primary and the other half from secondary schools (Table 1).

For statistical analyses, we used the IBM SPSS Statistics for Windows, Version 22.0 (IBM Corp. Released 2017, Armonk, NY: IBM Corp.). When evaluating questionnaires, differences in proportions of the correct answers between measurement times were evaluated using two-tailed McNemar's test stratified on the age groups (i.e. school levels). When analysing hand scanning results, the rate of error on the most frequently missed areas according to the literature was calculated for each individual as the number of error points in the areas known to be the most frequently missed ones (the thumb, the near-thumb area and the fingertips on the dorsal part of the right hand) per the number of all error points. The relationship between the rate of error 
Table 1. Division of the sample of SHWP in the different school types by research method and sex (per person and rate; $N=464$ )

\begin{tabular}{|c|c|c|c|c|c|c|c|}
\hline \multirow{3}{*}{\multicolumn{2}{|c|}{ Characteristics of sample }} & \multicolumn{6}{|c|}{ Types of school } \\
\hline & & \multicolumn{2}{|c|}{ Lower primary school } & \multicolumn{2}{|c|}{ Upper primary school } & \multicolumn{2}{|c|}{ Secondary school } \\
\hline & & $\begin{array}{c}\text { Per } \\
\text { person }\end{array}$ & $\begin{array}{l}\text { Rate in sub- } \\
\text { samples (\%) }\end{array}$ & $\begin{array}{c}\text { Per } \\
\text { person }\end{array}$ & $\begin{array}{l}\text { Rate in sub- } \\
\text { sample (\%) }\end{array}$ & $\begin{array}{l}\text { Per } \\
\text { person }\end{array}$ & $\begin{array}{l}\text { Rate in sub- } \\
\text { sample (\%) }\end{array}$ \\
\hline \multirow{2}{*}{$\begin{array}{l}\text { Research } \\
\text { methods }\end{array}$} & Filling questionnaires & 128 & 100.0 & 103 & 100.0 & 233 & 100.0 \\
\hline & $\begin{array}{c}\text { Measurement by } \\
\text { Semmelweis Scanner }\end{array}$ & 128 & 100.0 & 102 & 99.0 & 99 & 42.4 \\
\hline \multirow[t]{2}{*}{ Sex } & Male & 60 & 46.9 & 40 & 39.2 & 99 & 42.5 \\
\hline & Female & 68 & 53.1 & 62 & 60.8 & 134 & 57.5 \\
\hline
\end{tabular}

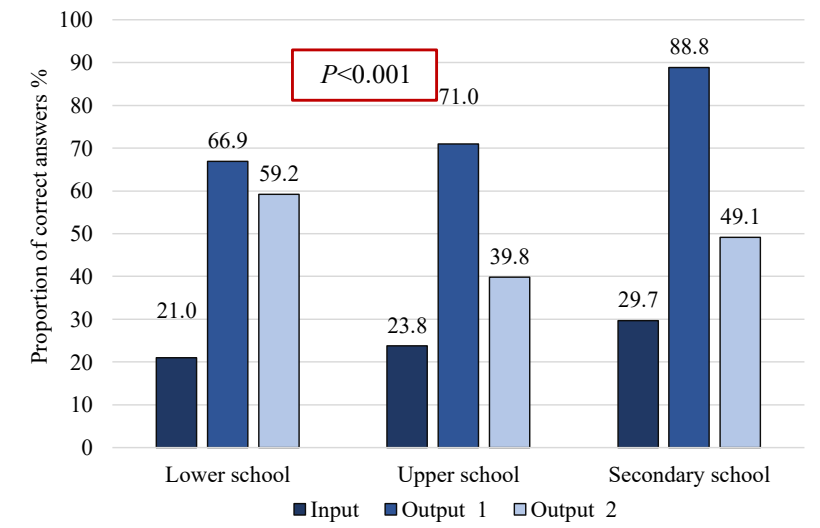

"What kind of soap should be used in everyday life?" (Proportion of correct answers \%, $n=458)$

Fig. 1. Children's soap choice for daily use

on the most frequently missed areas and theoretical knowledge (i.e. whether an individual knows which are the most frequently missed areas or not), gender and age were evaluated using simple linear regression models. Throughout the analysis, $P<0.05$ was considered to indicate statistical significance.

\section{RESULTS}

\section{Knowledge and health behaviour regarding handwashing before and after the intervention}

At Input, the proportion of the correct answers regarding the question about using the proper soap (What kind of soap should be used in everyday life? Bar soap/Scented soap/ Antiseptic soap/Liquid soap) - Liquid soap being the correct answer - was $21.0 \%$ at lower primary school, $23.8 \%$ in upper primary school and $29.7 \%$ in secondary school (Fig. 1). At Output 1, the proportion of the correct answers increased in every age group $(66.9 \%, 71.0 \%$ and $88.8 \%$; two-tailed exact McNemar's test $P<0.001$ in all age groups). At Output 2, the proportion of the correct answers decreased compared to Output 1 (59.2\%, 39.8\% and 49.1\%), but were still higher than before SHWP $(P<0.001$ and $P<0.010$, respectively). We would like to highlight that the most popular wrong answer regarding the question about the proper soap was

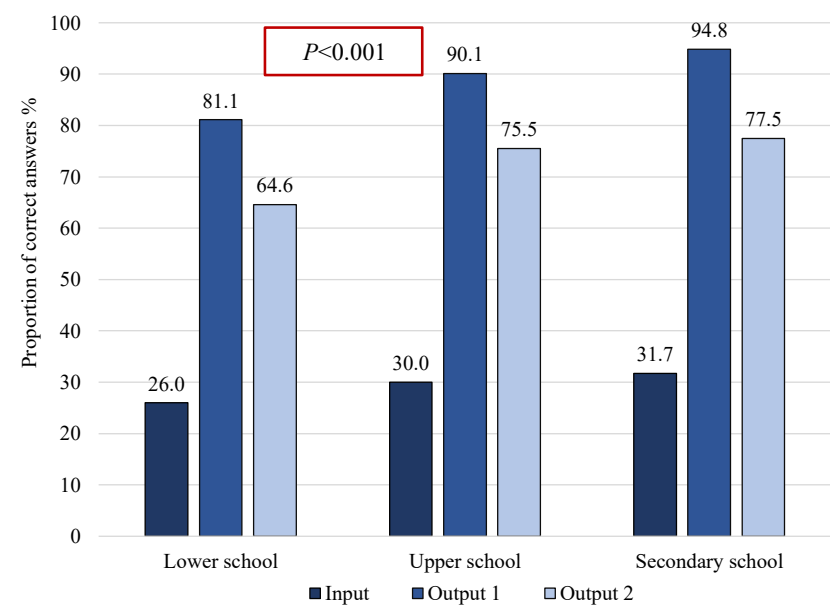

"Which hand-drying method is the most sufficient regarding the cleanliness of the hand?" (Proportion of correct answers \%, $n=460$ )

Fig. 2. The most sufficient hand-drying method

antiseptic soap in all the three age groups $(68.5 \%, 71.3 \%$ and $61.6 \%)$. Thanks to the peer education programme we were able to correct this popular misconception.

The proportion of the correct answers regarding the healthiest option, (Which hand-drying method is the most sufficient regarding the cleanliness of the hand? Electronic hand dryer/Towel/Paper towel/My clothes if they're clean) paper towel was chosen correctly in $26.0 \%$ in lower primary school, $30.0 \%$ in upper primary school and $31.7 \%$ in secondary school at Input (Fig. 2). At Output 1 the percentages increased to $81.1 \%, 90.1 \%$ and $94.8 \%$, and these differences were significant compared to the Input measurement at every school level ( $P<0.001$ in all age groups). Participants' knowledge decreased at Output 2 (64.6\%, 75.5\% and 77.5\%), although these percentages were higher compared to the Input measurement $(P<0.001$ in all age groups).

At Input the proportion of correct answers (i.e. between 20 and $30 \mathrm{~min}$ ) regarding the proper length of handwashing (For how long do we have to count during the sufficient handwashing? We have to count at least ...... when we wash our hands carefully.) was $34.7 \%$ among lower primary school students, $29.6 \%$ in the upper primary school and $36.1 \%$ in the secondary school group. At Output 1 the percentages increased at every school level $(79.2 \%, 87.3 \%$ and $88.0 \%, P<0.001$ in all age groups). At Output 2 this 
knowledge decreased to $55.9 \%, 65.1 \%$ and $68.4 \%$, although these percentages were still higher compared to the Input measurement $(P<0.001$ in all age groups).

Since the changes of health behaviour (For how long do you usually wash your hands? I count at least to 3 during handwashing/I count at least to 10 during handwashing/I count at least to 20 during handwashing/I count at least to 60 ) could be detected only in the long run, that is why the results of health behaviour questions were compared only at Input and Output 2 measurements. Before the handwashing programme $48.0 \%$ of lower primary school students washed their hands for at least $20 \mathrm{sec}$ based on self-assessment. This proportion was only $25.0 \%$ among upper primary school students and $26.4 \%$ in the group of secondary school students. At Output 2 these values grew to $58.4 \%, 45.6 \%$ and $35.3 \%$; however, the differences between the two time points were significant only in case of the upper primary school and secondary school students $(P<0.001$ and $P=0.014$, respectively).

About washing hands after visiting a sick person (Do you usually wash your hands after visiting a sick person? Yes/No), most of the students had positive health behaviour even at Input. $92.1 \%$ of the participants from lower primary school, $91.8 \%$ from upper primary school and $88.3 \%$ from secondary school usually wash their hands after visiting a sick person. At Output 2, the proportion of the correct answers remained the same in the case of lower primary school participants, it decreased to $89.3 \%$ among upper primary school students (the difference was not significant; $P=$ 0.79), while it increased to $94.0 \%$ in the group of secondary school students $(P=0.019)$.

Handwashing before toilet usage (Do you usually wash your hands before using the toilet? Yes/No) was the least evident among the participants. At Input, the proportion of those who wash their hands before using the toilet was $22.8 \%$ in the case of lower primary school students, $12.9 \%$ among upper primary school students and $15.9 \%$ in the secondary school group. At Output 2 the percentages increased in every age group $(40.3 \%, 37.3 \%$ and $17.6 \%)$; however, the differences between the two time points were significant only in case of the lower primary school and upper primary school students $(P<0.001$ in both cases $)$.

\section{Handwashing skills}

Before presenting the hand scanning results, we have to note that $91.0 \%$ of our sample was right-handed and $9 \%$ was lefthanded. The average error point measured during manual scanning of the total 20 error points were $2.46(S D=2.46)$ on the right hand and $2.16(S D=2.31)$ on the left hand.

Examination of frequently missed areas - as reported in previous literature - in our sample. In our study of the children population, we looked at frequently missed areas found in adults in previous studies (See in Introduction) such as the thumb, the near-thumb area and the fingertips on the dorsal part of the right hand. 197 students who made at least one mistake during the Input hand scan were
Table 2. Number of all errors in different parts and areas of the hand during the Input hand scan measurement

(per person; $N=224$ )

\begin{tabular}{lcccc}
\hline Area & $\begin{array}{c}\text { Left } \\
\text { dorsum }\end{array}$ & $\begin{array}{c}\text { Right } \\
\text { dorsum }\end{array}$ & $\begin{array}{c}\text { Left } \\
\text { palm }\end{array}$ & $\begin{array}{c}\text { Right } \\
\text { palm }\end{array}$ \\
\hline Fingertips & 74 & 81 & 0 & 0 \\
Thumb & 124 & 135 & 1 & 0 \\
Index finger & 48 & 43 & 0 & 1 \\
Middle finger & 32 & 38 & 0 & 1 \\
Ring finger & 34 & 41 & 0 & 1 \\
Little finger & 49 & 56 & 1 & 1 \\
Medial dorsum & 31 & 31 & 0 & 0 \\
Distal dorsum & 27 & 38 & 0 & 1 \\
Lateral dorsum & 33 & 46 & 0 & 0 \\
Proximal & 29 & 38 & 0 & 0 \\
$\quad$ dorsum & & & & \\
\hline
\end{tabular}

examined. In $60.40 \%(n=119)$ of these students at least half of the mistakes were found in the most frequently missed areas in adult population (See in Introduction). Furthermore, it could also be observed that $30.46 \%$ of the students $(n=197)$ had error points only in the areas in question.

Based on the cumulative error rates of the 40 regions of the hand, we examined how many students made errors in each area with the help of hand scanning. A large number of error points were observed at the thumb and fingertips, which is in accordance with the literature, but in the study population lateral dorsum was overtaken by little finger on both the right and left dorsal areas. The back of the index finger on the left hand was also ahead of lateral dorsum. The number of error points on both palms is negligible (Table 2).

Factors influencing Input hand scanning in the most frequently missed areas. Next, we aimed at investigating whether certain factors influenced the high error rate in the most frequently missed areas observed at the Input hand scanning measurements. Therefore, error rates of Input hand scanning have been examined from the aspects of theoretical knowledge (i.e. whether a student knows which are the most frequently missed areas or not), gender and age. First, we calculated the rate of error on the most frequently missed areas for each individual as the number of error points in the areas known to be the most frequently missed ones (the thumb, the near-thumb area and the fingertips on the dorsal part of the right hand) per the number of all error points. Next, we evaluated the relationship between the rate of error on the most frequently missed areas and theoretical knowledge, gender and age using simple linear regression models. No significant association was found between the rate of error on the most frequently missed areas and theoretical knowledge $(F(1,195)=0.01, P=0.920$, coefficient $=0.00$; CI (95\%): -0.09 to 0.08$)$. Therefore, it cannot be stated that those who knew them were less likely to make mistakes in the given areas.

Similarly, the gender of the students did not significantly influence the rate of error on the most frequently missed areas $(F(1,195)=0.37, P=0.546$, coefficient $=0.03$; CI (95\%): -0.06 to 0.11$)$. 


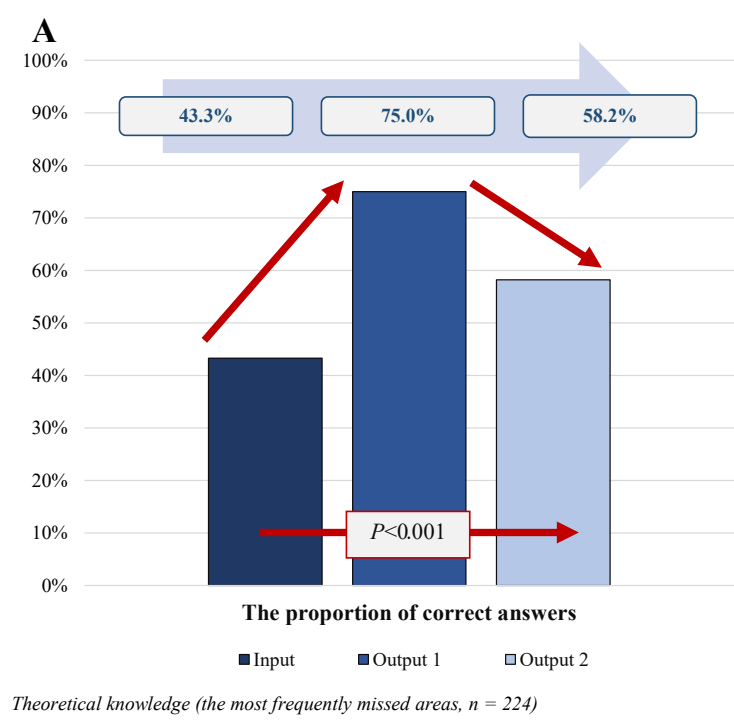

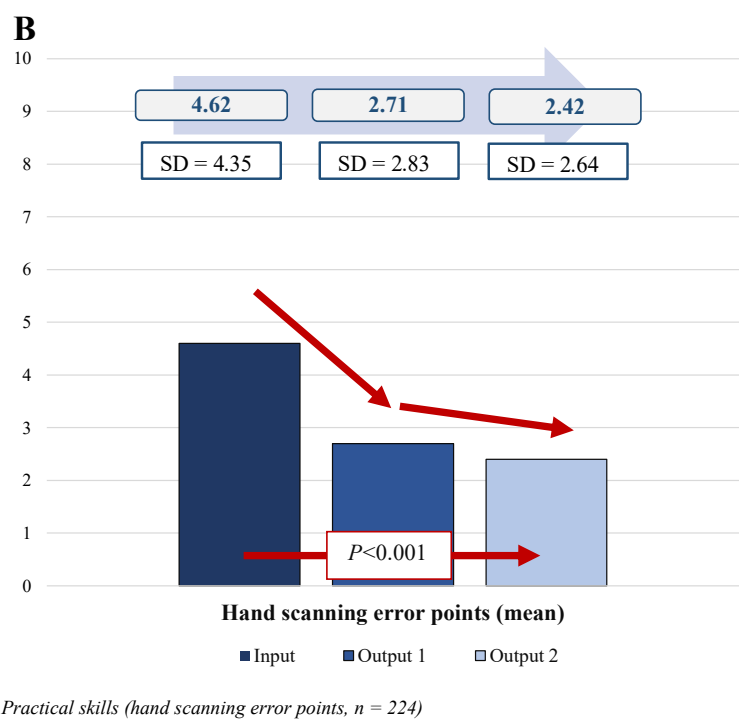

Fig. 3. Comparison of theoretical knowledge and practical skills. (A) The proportion of correct answers. (B) Hand scanning error points (mean)
Age, on the other hand, significantly influenced the rate of error on the most frequently missed areas $(F(1,195)=$ $\left.4.57, P=0.033, R^{2}=0.023\right)$, as each year of life increased the error rate by 0.02 , suggesting that as the age grows it is increasingly more common for students to make mistakes in the areas characteristic in adults (coefficient $=0.02$; CI (95\%): -0.00 to 0.03 ).

The multivariate regression model (i.e. including all three variables) was not significant $(F(3,193)=1.65$, $P=0.180)$.

\section{Improvement of theoretical knowledge over time}

Theoretical knowledge was examined on the basis of the most frequently missed hand areas (Fig. 3A). At the time of the Input measurement, $43.3 \%$ of the students was aware of the correct answer, which number increased to three quarters of the students by the assessment at Output 1 , and the difference was highly significant (two-tailed exact McNemar's test $P<0.001)$. At Output 2 , the rate of correct answers dropped to $58.2 \%$, but still reached a higher level than before the programme $(P<0.001)$.

Improvement of practical skills over time. Practical skills were tested on the basis of mean errors in hand scanning (Fig. 3B). A repeated measure of ANOVA with a Greenhouse-Geisser correction determined that the mean errors of hand scanning differed statistically significantly between the three time points $(F(1.17,379.03)=32.360, P$ $<0.001)$. Post hoc tests using the Bonferroni correction revealed that SHWP resulted in a significant reduction of mean errors in hand scanning from Input to Output 1 $(4.62 \pm 4.35$ error points vs. $2.71 \pm 2.83$ error points, respectively), which was statistically significant $(P<$ 0.001 ). Moreover, at Output 2, the mean error points reduced further to $2.42 \pm 2.64$ points, which was statistically significantly different from Input $(P<0.001)$, but not from Output $1(P=0.613)$.

\section{DISCUSSION}

According to the literature on adults, right-handed people have more areas left-out on the right dorsum [4, 5]; however, in our study population, no difference was found between right- and left-hand scans before the intervention. Theoretical knowledge and practical skills were improved at Output 1 compared to the Input outcomes. At output 2, there is a decline in theoretical knowledge - although the results are still better than the Input scores - while handwashing skills have clearly improved. Interactive skills development, considering the age of the children, has proved to be truly effective in the long run; the theory transfer tasks have also improved, but to a lesser extent.

When examining the missed areas, considering the literature $[4-7,19]$ it can be seen that most of the students' missed areas are only partially identical to the areas missed by adults. The area around the thumb is less properly washed, but new unwashed regions (i.e. not common in adults) appear on the fingers, indicating that children may have different habits. Looking at age, it can be observed that as age progresses the areas skipped by children over the course of their lives are increasingly aligned with those skipped by adults.

In the case of the soap used in everyday life, the values for correct knowledge were surprisingly low and no significant difference could be detected between the different age groups. Prior to the intervention, the rate of incorrect responses was high. Most have labelled antiseptic soap as the right choice for everyday handwashing, while it can damage the skin microbiota, so should be used only when warranted. 
Following the intervention, the proportion of correct answers became statistically much higher.

On the questions of the most appropriate hand wiping method $[30,31]$ at Input less than half of the students knew that paper towels were recommended. Among the other options (electric hand dryer, private linen, cloth towels), the answers were divided, indicating that only a small proportion of students had sufficient knowledge on the subject matter.

According to the World Health Organization, after a patient visit, handwashing is necessary for preventive purposes [28]. Most students were aware of this information and acted accordingly. Publications about hospital hand hygiene may have had a positive impact on this form of student health behaviour.

Handwashing before using the toilet showed a low frequency. A small percentage of students said they wash their hands before going to the bathroom. In the long run, this health behaviour was also positively influenced, doubling in the lower primary school groups, increasing significantly in the upper primary school groups, and having little influence in this regard in secondary school. However, the majority of students still do not follow good health behaviours [28].

To sum up, although the lower primary school students did not answer the theoretical questions in the highest proportion, in practice they still wash their hands mostly as they self-declare. According to the ECDC statement, 20 seconds is sufficient to carry out a proper hand hygiene routine [31]. Due to the time needed to record the change in behaviour, we compared our data only to the Output 2 questionnaires. At Output 2, although the proportion with regards to the length of handwashing increased in all age groups, it was still below expectations.

At Input and Output 1, lower primary school students are washing hands for even a higher amount of time than they know it would be adequate to maintain health. There was no such correlation between upper primary and secondary school students.

\section{CONCLUSIONS}

There are differences in the hand hygiene skills of child and adult populations, which needs to be taken into consideration when designing age-specific health promotion programmes.

The peer education programme proved to be effective because we could see an improving trend in both theoretical and practical skills following the programme. Although at Output 2 theoretical knowledge decreased, the practical skills improved slightly.

In the case of programmes aimed at developing practical skills, it must be taken into consideration that in order to improve and maintain good practices in the long term, integrating theoretical and practical knowledge into the curriculum would be beneficial.
As for their health behaviour, students tend to miss significant handwashing occasions in their daily practice. These are worth paying close attention to and informing educational institutions and their teachers should be continued.

Ethical approval: Our research is morally acceptable and we follow the World Medical Association's Declaration of Helsinki and requirements of all applicable local and international standards. The Hungarian Medical Research Council Research Ethics Committee approved this research (No 18241-2/2017/EKU).

Authors' contribution: ZZM: data collecting procedure, data entry, statistical analysis of knowledge data, writing some parts of sections. LV: data collecting procedure, data entry, statistical analysis of handwashing skill data, writing some parts of sections, GGY: data collecting procedure, data entry, statistical analysis, writing some parts of sections. ÁL: data collecting procedure, data entry, evaluate of scanner data, checking of the manuscript. EG: finding references; complement of Introduction section, checking of the manuscript. ÁLJ: complement of Results section, checking of the manuscript. RF: data collecting procedure, references, checking of the manuscript. AG: statistical analysis, checking of the manuscript. AF: complement of Results, Discussion and Conclusion sections, checking of the manuscript. HJF: data collecting procedure, complementing Materials and methods; checking of the manuscript; coordination of authors' contributions.

Conflict of interest/Funding: The authors declare no conflict of interest. This study was funded by the Content Pedagogy Research Program of the Hungarian Academy of Sciences.

Acknowledgements: We express special thanks to Handi$\mathrm{nScan}$ Zrt. and Ecolab-Hygiene Kft. for the personal support they provided our study with.

\section{REFERENCES}

1. Larson E. A causal link between handwashing and risk of infection? Examination of the evidence. Infect Control 1988;9(1):28-36.

2. Aiello AE, Larson EL. Causal inference: the case of hygiene and health. Am J Infect Control 2002;30(8):503-11. https://doi.org/10. 1067/mic.2002.124585.

3. Barker J, Stevens D, Bloomfield SF. Spread and prevention of some common viral infections in community facilities and domestic homes. J Appl Microbiol 2001;91(1):7-21. https://doi.org/10.1046/j. 1365-2672.2001.01364.x.

4. Taylor LJ. An evaluation of handwashing techniques-1. Nurs Times 1978;74(2):54-5.

5. Hardyck C, Petrinovich LF. Left-handedness. Psychol Bulletin 1977;84(3):385-404.

6. Szilágyi L, Haidegger T, Lehotsky A, et al. A large-scale assessment of hand hygiene quality and the effectiveness of the "WHO6-steps". BMC Infect Dis 2013;13:249. https://doi.org/10.1186/1471-2334-13-249. 
7. Vanyolos E, Peto K, Viszlai A, et al. Usage of ultraviolet test method for monitoring the efficacy of surgicalhand rub technique among medical students. J Surg Educ 2015;72(3):530-5. https://doi.org/10. 1016/j.jsurg.2014.12.002.

8. Ali MM, Verrill L, Zhang Y. Self-reported hand washing behaviors and foodborne illness: a propensity score matching approach. J. Food Prot 2014;77(3):352-8. https://doi.org/10.4315/0362-028X.JFP-13-286.

9. Sakihama T, Honda H, Saint S. et al. Hand hygiene adherence among health care workers at japanese hospitals: a multicenter observational study in Japan. J Patient Saf 2016;12(1):11-7. https:// doi.org/10.1097/PTS.0000000000000108.

10. Løyland B, Peveri AM, Hessevaagbakke E, Taasen I, Lindeflaten K. Students' observations of hand hygiene in nursing homes using the five moments of hand hygiene. J Clin Nurs 2020;29(5-6):821-30. https://doi.org/10.1111/jocn.15136.

11. Sultana M, Mahumud RA, Sarker AR, Hossain SM. Hand hygiene knowledge and practice among university students: evidence from Private Universities of Bangladesh. Risk Manag Healthc Policy 2016;9:13-20. https://doi.org/10.2147/RMHP.S98311.

12. Early E, Battle K, Cantwell E, English J, Lavin JE, Larson E. Effect of several interventions on the frequency of handwashing among elementary public-school children. Am J Infect Control. 1998;26(3): 263-9. https://doi.org/10.1016/s0196-6553(98)80011-4.

13. Chittleborough CR, Nicholson AL, Basker E, Bell S, Campbell R. Factors influencing hand washing behaviour in primary schools: process evaluation within a randomized controlled trial. Health Educ Res. 2012;27(6):1055-68. https://doi.org/10.1093/her/cys061.

14. Alveolar and cystic echinococcosis-Two disease. [Internet]. Geneva: WHO cited [2019 June 16]. Available from: http://www. who.int/echinococcosis/Life_cycle_Echinococcosis_with_ intervention_points.pdf.

15. Nandrup-Bus I. Comparative studies of hand disinfection and handwashing procedures as tested by pupils in intervention programs. Am J Infect Control 2011;39(6):450-5. https://doi.org/10. 1016/j.ajic.2010.10.023.

16. Randle J, Metcalfe H, Webb JCA, et al. Impact of an educational intervention upon the hand hygiene compliance of children. J Hosp Infect 2013;85(3):220-5. https://doi.org/10.1016/j.jhin.2013.07.013.

17. Willmott M, Nicholson A, Busse H, MacArthur GJ, Brookes S, Campbell R. Effectiveness of hand hygiene interventions in reducing illness absence among children in educational settings: a systematic review and meta-analysis. Arch Dis Child 2016;101(1): 42-50. https://doi.org/10.1136/archdischild-2015-308875.

18. Wang Z, Lapinski M, Quilliam E, Jaykus LA, Fraser A. The effect of hand-hygiene interventions on infectious disease-associated absenteeism in elementary schools: a systematic literature review. Am J Infect Control 2017;45(6):682-9. https://doi.org/10.1016/j.ajic.2017.01.018.

19. Pittet D, Boyce JM. Hand hygiene and patient care: pursuing the Semmelweis legacy. Lancet Infect Dis. 2001;1: 9-20. https://doi.org/ 10.1016/S1473-3099(09)70295-6.

20. Armitage CJ, Conner M. Social cognition models and health behaviour: a structured review. Psychol Health 2000;15(2):173-89. https://doi.org/10.1080/08870440008400299.
21. Godin G, Bélanger-Gravel A, Eccles M, Grimshaw J. Healthcare professionals' intentions and behaviours: a systematic review of studies based on social cognitive theories. Implement Sci 2008;3:36. https://doi.org/10.1186/1748-5908-3-36.

22. Feith HJ, Lukács Á, Gradvohl E, et al. Health education - responsibility - changing attitude. A new pedagogical and methodological concept of peer education. Acta Univ Sapientiae, Social Analysis 2018;8(1):55-74. https://doi.org/10.2478/aussoc-2018-0004.

23. Feith HJ, Darvay S, Lukács Á, Falus A. Hatékonyság és reflexió - a kortársoktatás pedagógiai módszere az egészségségfejlesztés területén. [Effectiveness and reflection-pedagogical methods of peer education in health promotion]. Magyar Tudomány 2020;181(1):79-89. [Article in Hungarian]. https://doi.org/10.1556/2065.181.2020.1.8.

24. Lehotsky Á, Falus A, Lukács Á, et al. Kortárs egészségfejlesztési programok közvetlen hatása alsó tagozatos gyermekek kézhigiénés tudására és megfelelő kézmosási technikájára. [Direct effect of contemporary health education programmes on the knowledge about hand hygiene and technique of hand washing in primary school age children]. Orv Hetil 2018;159(12):485-90. [Article in Hungarian]. https://doi.org/10.1556/650.2018.31031.

25. Feith HJ, Lehotsky Á, Lukács Á, et al. Methodological approach to follow the effectiveness of a hand hygiene peer education training programme at Hungarian schools. DHS 2018;1(2):39-43. https:// doi.org/10.1556/2066.2.2018.13.

26. Benè KL, Bergus G. When learners become teachers: a review of peer teaching in medical student education. Fam Med 2014;46(10): 783-7.

27. Feith HJ, Melicher D, Máthé G, et al. apasztalatok és motiváltság: magyar középiskolások véleménye az egészségvédő programokról. [Experience and motivation: opinion of Hungarian high school students about health promotion programs]. Orv Hetil 2016;157(2): 65-9. https://doi.org/10.1556/650.2015.30338.

28. WHO Guidelines on Hand Hygiene in Health Care. [Internet]. Geneva: WHO. [cited 2019 Jun 16]. Available from: https://apps. who.int/iris/bitstream/handle/10665/44102/9789241597906_eng. pdf;jsessionid = B6523C32C4B955DB54808691EDBD1FEB? sequence $=1$.

29. Lehotsky Á, Szilágyi L, Demeter-Iclanzan A, Haidegger T, Wéber Gy. Education of hand rubbing technique to prospective medical staff employing UV-based digital imaging technology. Acta Microbiol Immunol Hung 2016;63(2):217-28. https://doi.org/10. 1556/030.63.2016.2.6.

30. Todd ECD, Michaels BS, Smith D, Greig JD, Bartleson CA. Outbreaks where food workers have been implicated in the spread of foodborne disease, part 9: washing and drying of hands to reduce microbial contamination. J Food Prot 2010;73(10):1937-55. https:// doi.org/10.4315/0362-028x-73.10.1937.

31. Redway K, Fawdar S. European tissue symposium: a comparative study of three different hand drying methods: paper towel, warm air dryer, jet air dryer. [Internet]. London: School of Biosciences, University of Westminster. [cited 2019 Jun 16]. Available from: http:// www.europeantissue.com/pdfs/090402-2008\%20WUS\%20Westminster \%20University\%20hygiene\%20study,\%20nov2008.pdf.

Open Access. This is an open-access article distributed under the terms of the Creative Commons Attribution 4.0 International License (https://creativecommons.org/ licenses/by/4.0/), which permits unrestricted use, distribution, and reproduction in any medium, provided the original author and source are credited, a link to the CC License is provided, and changes - if any - are indicated. (SID_1) 